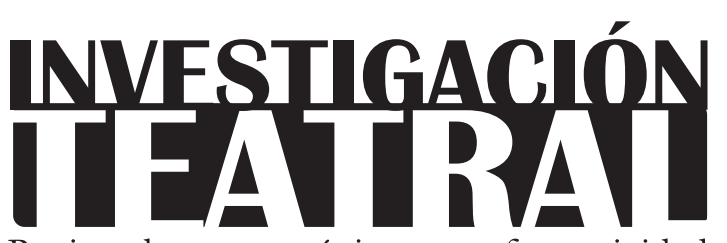

Revista de artes escénicas y performatividad

Vol. 9, Núm. 14

octubre 2018-marzo 2019

Segunda época

ISSN impreso: 1665-8728

ISSN electrónico: 2594-0953

Universidad Veracruzana
Reseña de la

puesta en escena:

La irrisión de la

masculinidad

hegemónica en la

puesta en escena de

Prata Paraíso, de João de Ricardo (Brasil)

Daniel dos Santos Colin*

\footnotetext{
* Universidade do Estado de Santa Catarina, Brasil. e-mail: danielcolin@gmail.com
}

Recibido: 18 de abril de 2018

Aceptado: 02 de agosto de 2018 


\section{La irrisión de la masculinidad hegemónica en la puesta en escena de Prata Paraíso, de João de Ricardo (Brasil)}

odd Duncan, un joven artista homosexual, vuelve al seno de su adinerada familia después de años apartado para hacerles una impactante declaración: "yo tengo sida". Esta es la base elemental del texto Pterodactyls, una comedia mordaz en tres actos escrita por el dramaturgo estadounidense Nicky Silver en el año 1993, misma que, como se detallará a continuación, fue adaptada por el el director brasileño João de Ricardo en el año 2017.

A medida en que desequilibra la cotidianeidad aparentemente perfecta de los Duncan, Todd se topa con el rechazo de sus familiares: el padre narcisista, Arthur, niega la homosexualidad del hijo a toda costa; Grace, la madre alcohólica, sentencia el estado terminal del primogénito y resuelve planear su entierro como si fuera un gran evento para la high society; la otra hija de la pareja, la hipocondriaca Emma, ni siquiera se acuerda del hermano descarriado de tan absorta que está en su relación con Tommy, el empleado doméstico de la casa. Sin embargo, al envolverse sexualmente con el prometido de su hermana, Todd desencadena las muertes de todos los otros personajes hasta convertirse en el último sobreviviente dentro de la casa.

En esta obra dramática, Silver utiliza la parábola del hijo pródigo para tejer una crítica satírica de las costumbres heteronormativas de su país, y así discutir el descenso de la condición humana al compararla con el proceso de extinción de los dinosaurios. Esto se ve representado por el esqueleto de un tiranosaurio rex que Todd descubre enterrado en el jardín de los Duncan.

El director João de Ricardo (JdR) utiliza las acciones propuestas por Nicky Silver en Pterodactyls para elaborar el provocador espectáculo Prata Paraíso, una obra performa- 
INVESTIGACIÓNTEATRAL

Revista de artes escénicas y performatividad

Vol. 9, Núm. 14

octubre 2018-marzo 2019
La irrisión de la masculinidad hegemónica

en la puesta en escena de Prata Paraíso

Daniel dos Santos Colin

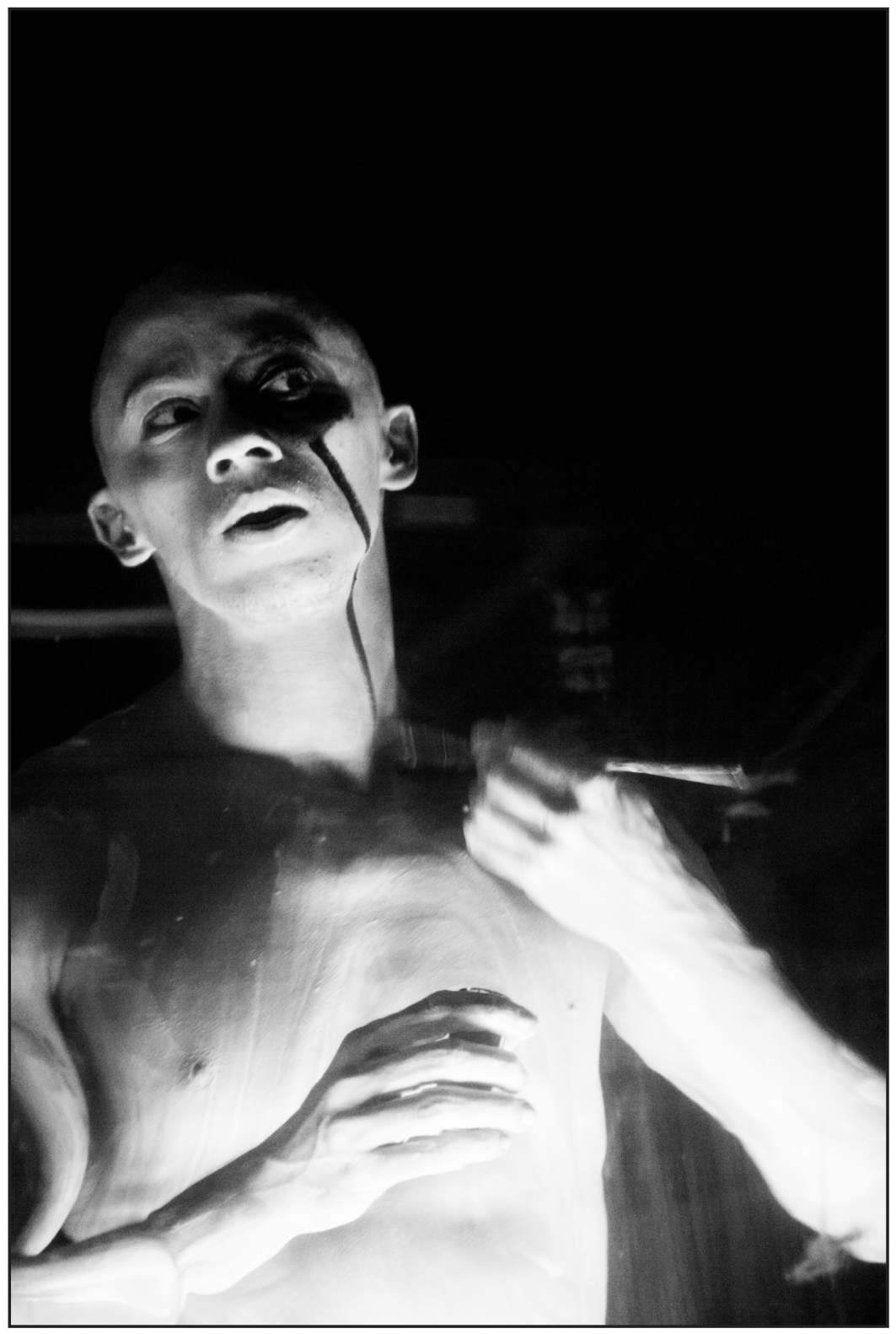

Andrew Tassinari

maquillándose frente al espejo. Prata Paraíso. Porto Alegre, 2017. Fotografía de Morgana Mazzon.

tiva que traslada la trama hacia circunstancias geopolíticamente localizadas en Brasil. La adaptación de JdR potencializa algunas cuestiones queer (referentes a políticas y discursos de diversidad sexual) apenas insinuadas en el texto dramático original, esto al centrar toda su puesta en escena en la figura emblemática de Tod (en el original Todd), personaje al cual nuestro director le sustrae una letra del nombre ("D") para permitir que el protagonista 
simbolize la muerte en sí. ${ }^{1}$ En este contexto, Tod puede ser perfectamente comprendido como un "personaje-director", teniendo en vista que todos los elementos escénicos dispuestos en escena parecen converger hacia sus voluntades y deseos: objetos, vestuario, maquillaje, reflectores de led, lámparas fluorescentes y cámara filmadora digital permiten que Tod presente al público su ceremonia final y apoteósica.

El espacio escénico se completa con una pared negra al fondo, en la cual son proyectados videos pregrabados o manipulados en vivo, y tres espejos grandes, que son utilizados por los actores para maquillarse a cada cambio de acto. El elenco es formado por los performers Andrew Tassinari, Douglas Jung y Eduardo d'Ávila, que se alternan entre los cinco personajes de la obra utilizando para eso sus cuerpos, casi todo el tiempo desnudos, adornados apenas con maquillaje de colores, vestuarios simbólicos (faldas, tapados de piel, sacos) y eventuales pelucas.

Además de los tres actores constatamos nítidamente la presencia de João de Ricardo en el espacio escénico, actuando como director-performer y cumpliendo la función de operador de sonido, de luz, de video y de manipulador del juego escénico. Finalmente, el público se sienta en el suelo, muy próximo al elenco, teniendo en cuenta que el trabajo es presentado en una sala diminuta de aproximadamente $60 \mathrm{~m}^{2}$.

El espectáculo se caracteriza como un ritual performativo y grotesco en homenaje a la transitoriedad de todo, sostenido por tres pilares conceptuales: la muerte propiamente dicha, el personaje Tod como centro de la acción y los tres performers. La primera de estas instancias corresponde a las simbologías asociadas a la noción de muerte, expresadas tanto por las imágenes proyectadas (referencias fúnebres como cementerios, lápidas y esqueletos) como por las representaciones de diversas entidades (como el orixá Obaluaie o la figura pagana Baphomet) que surgen en el escenario en los momentos en que el virus viH es transmitido sexualmente por alguno de los personajes. La obsesión mortuoria inculcada en todos los personajes (incluso en Tod, pues él mismo personifica la propia muerte) destaca una atmósfera ritual y lúgubre en la obra, a pesar de excelentes momentos cómicos que puntualizan la escenificación.

El segundo cimiento que sostiene el montaje es la figura de Tod y su condición de artista gay seropositivo. Tod encuentra voz en otros artistas reales que fallecieron a consecuencia del ViH y que aparecen figurativamente en la escenificación, sobre todo el alemán Klaus Nomi y sus óperas (con especial aprecio al aria Dido's Lament de la obra Dido und Aeneas) y el compositor brasileño Cazuza a través de su canción paradigmática Cobaias de Deus. A través de este recurso, Prata Paraíso refuerza el protagonismo del

$1 \quad$ Tod significa muerte en alemán. 
INVESTIGACIÓNTEATRAL

Revista de artes escénicas y performatividad

Vol. 9, Núm. 14

octubre 2018-marzo 2019
La irrisión de la masculinidad hegemónica en la puesta en escena de Prata Paraíso

Daniel dos Santos Colin

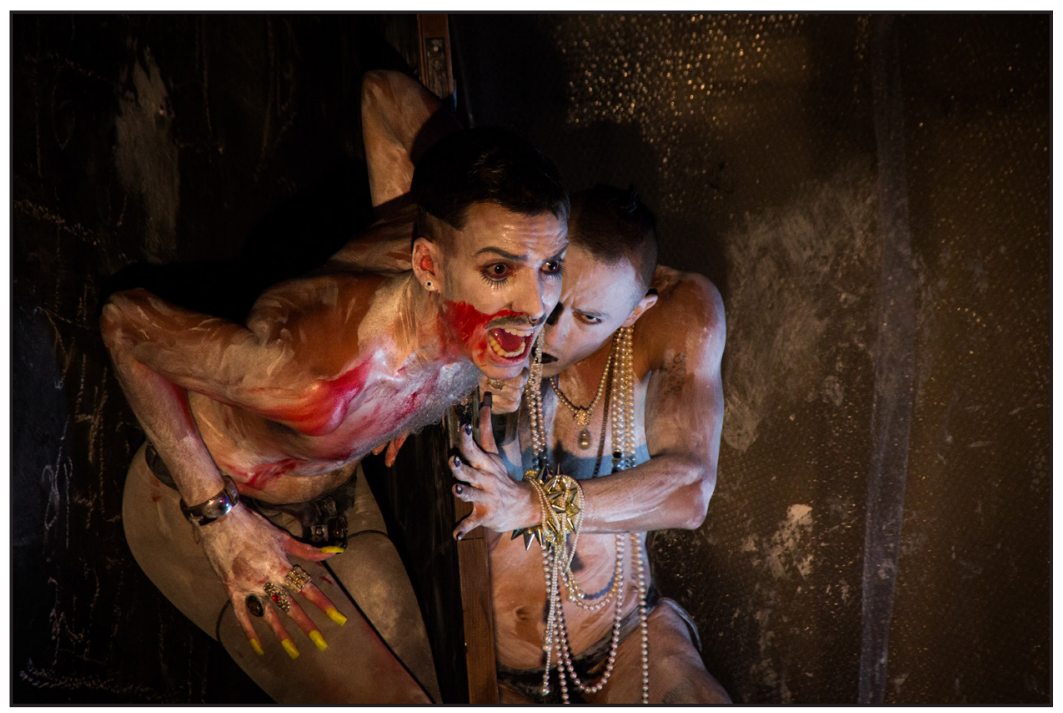

Los actores Eduardo d'Ávila y Andrew Tassinari durante la escena en que la familia Duncan se aterroriza con el regreso de Tod. Prata Paraíso. Porto Alegre, 2017. Fotografía de Morgana Mazzon.

cuerpo queer en el espectáculo y homenajea justamente a aquellos autores que le sirven como referencia artística, exaltando individuos cuyas carreras fueron menospreciadas en virtud de su enfermedad.

Los performers se configuran como el tercer elemento al traducir con sus cuerpos una rotación frenética entre los personajes de la obra. De esta forma son constantemente presentados a través movimientos coreográficos y libidinosos, así como al desestructurar algunas nociones de género y de sexualidad, al deconstruir la figura masculina hegemónica a través del recurso del travestimiento, del uso de gestos femeninos en cuerpos idealizados (hombres blancos, delgados y jóvenes) y de la carnavalización de los binarismos de género a través de la exaltación al ano como potencia subversiva.

Sobre este tópico, podemos conjeturar que el culo/ano se configura como el elemento definidor de las nociones binarias de masculinidad (activo) y feminidad (pasivo), y considerado, por lo tanto, parte de un régimen cultural heterocentrado. En suma, el ano se caracteriza como eje determinante de lo que es ser un cuerpo valorado o un cuerpo menospreciado, de lo que es ser "maricón" o ser hetero, ya que la identidad sexual no es establecida por los genitales del sujeto, sino por su comportamiento pasivo o activo. ${ }^{2}$

2 Según los autores Sáez y Carrascosa, el ano, a pesar de no poseer género, se constituye como centro elemental en la constitución del actual sistema de sexo-género, ya que la identidad sexual no es establecida por los genitales del sujeto, sino por su comportamiento pasivo o activo; comportamientos asociados históricamente a una correlación de poder binário (sujeto-objeto). Para más información: Sáez, Javier y Sejo Carrascosa. Pelo cu: políticas anais. Belo Horizonte: Letramento, 2016. 
De este modo, podemos reflexionar acerca de la irrisión de la masculinidad hegemónica en Prata Paraíso con el auxilio de dos escenas específicas de la obra: aquella en la que el padre asedia a su propia hija en oposición a aquella en la cual el protagonista enfrenta a su progenitor. En la primera de ellas, Emma le cuenta a Tommy que el padre se le aparece todas las noches en su cuarto para abusarla sexualmente. En esta escena, podemos observar al actor Eduardo d'Ávila interpretando a la chica de rodillas frente a su padre, representado por Andrew Tassinari, el cual viste apenas un saco y una máscara de chivo, cuya acción principal es exhibir su pene flácido próximo al rostro de la hija. Como un símbolo "anti-pornográfico" ${ }^{3}$ el falo flácido no sostiene -iy hasta pone en jaque!- la virilidad que Arthur defiende como primordial para su condición de macho alfa.

En contraposición aparece la otra escena, una de las más antológicas de todo el espectáculo. Tod hace una declaración de apología a la pasividad al ser confrontado por su padre acerca de su hombría: cuando Douglas Jung (Arthur) le cuestiona al hijo si él ha sido penetrado por otros hombres, Andrew Tassinari (Tod) se frota un puñado de purpurina dorada en el culo, se postra en "cuatro patas" y, en esta posición, le vocifera al padre que no sólo es pasivo en sus relaciones sexuales, sino también cómo lo ha hecho diversas veces, hasta con ciudadanos desconocidos en espacios públicos.

Mientras su texto es dicho, podemos vislumbrar la cámara filmadora captando las imágenes de su ano abrillantado y proyectado en vivo sobre la pared al fondo del espacio escénico. El culo/ano de Tod ampliado en la pantalla se contrae y descontrae a medida que el discurso exaltado enumera cada una de las cópulas practicadas. Las contracciones anales reflejan los movimientos de la boca del actor, como si el culo/ano estuviera doblando y gritando las palabras proferidas en escena.

$\mathrm{Al}$ crear una relación entre estas escenas, podemos ponderar acerca de la representación de las masculinidades en Prata Paraíso. Si por un lado el espectáculo presenta al patriarca de la familia, heterosexual y macho-alfa representado por el pene blando e inofensivo, por otro lado tenemos al antagonista clásico, el "marica" afeminado, marginalizado, pasivo sexualmente, aquí elevado al puesto de protagonista de la obra, simbolizado por el culo/ano omnipresente y confrontacional, en una clara subversión de papeles sexuales y, consecuentemente, del dispositivo de la sexualidad hegemónica.

El ano aún se hace presente en la obra artística como elemento clave de la dramaturgia escénica, teniendo en vista que el público está siempre siendo "encarado" por el culo ex-

3 Denomino como "anti-pornográfico" el uso del pene flácido como foco de una escena potencialmente sexual, cuando sabemos que en la pornografia mainstream el cuerpo masculino surge representado por el falo siempre erecto, a perforar todos los tipos de orificios. El pene duro es el paradigma del macho activo para el porno comercial, sea en contexto hetero u homonormativo. 
INVESTIGACIÓNTEEATRAL

Revista de artes escénicas y performatividad

Vol. 9, Núm. 14

octubre 2018-marzo 2019
La irrisión de la masculinidad hegemónica en la puesta en escena de Prata Paraíso

Daniel dos Santos Colin

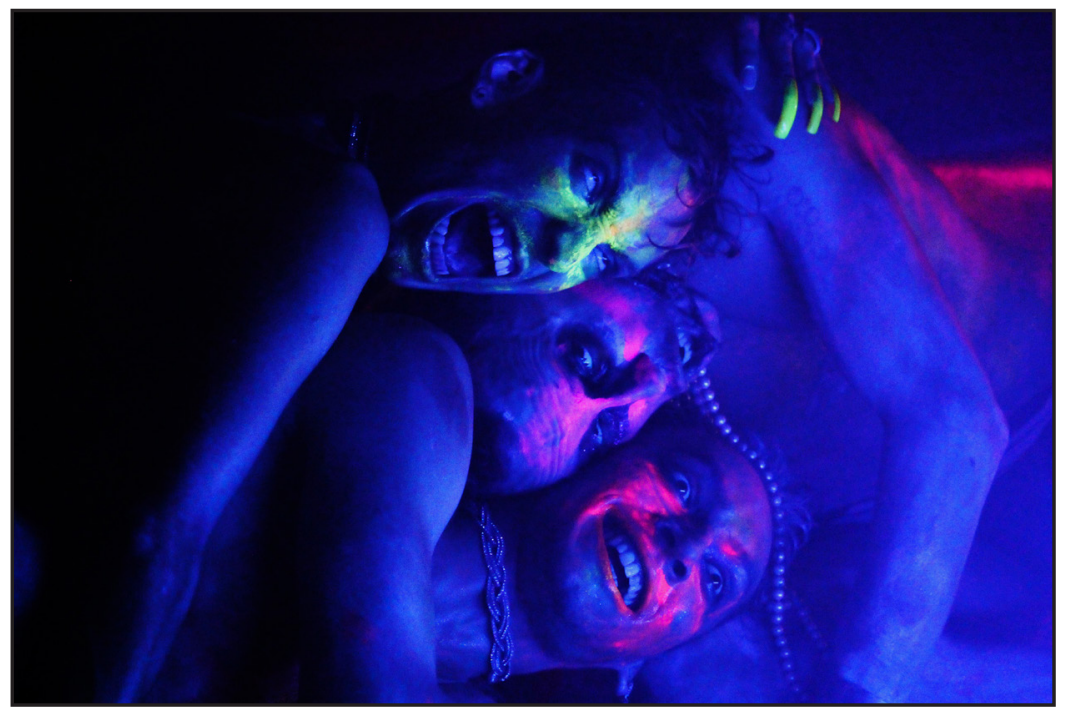

"Yo seguiré": las tres cabezas unidas representan la permanencia de Tod. Eduardo d'Ávila, Andrew Tassinari y Douglas Jung en escena. Prata Paraíso. Porto Alegre, 2017. Fotografía de Louise Carpanedo.

puesto de Andrew Tassinari, que viste durante toda la obra un calzoncillo jockstrap, a través del cual podemos vislumbrar sus nalgas desnudas y consecuentemente su orificio anal al aire. El culo se ostenta explícitamente en el trabajo de JdR como un gran agujero negro, apto a devorar la heteronormatividad y el conservadurismo, pero, al mismo tiempo, como un megáfono expuesto a través del cual el artista puede -iy debe! - expresarse.

Tod no duda en encerrar su performance tragicómica sobre los cadáveres de sus parientes y con el vaticinio: “¡Yo no me voy a morir! Cuando todos ustedes se transformen en polvo, yo seguiré. Cuando la Tierra sea barrida entera por el fuego, yo seguiré”. Su mensaje es evidente: el marica virulento, cuerpo queer indeseado y todo lo que él representa resistirá ¡y no será extinto como los dinosaurios!

A través de la furia anal de Tod, Prata Paraíso se afirma como una performance teatral decididamente "marica", en que la potencia queer desarticula ciertos discursos hegemónicos de masculinidades para problematizar la heteronormatividad patriarcal. Al centralizar el espectáculo en la figura de Tod y en su condición de artista gay, Prata Paraíso permite que el cuerpo queer asuma la escenificación y se configura como uno más de los espectáculos de la que podríamos denominar "estética marica" del director JdR, en los cuales la exaltación a la pasividad propone nuevas miradas sobre las prácticas y políticas anales. 
INVESTIGACIÓNTEATRAL

Revista de artes escénicas y performatividad

Vol. 9, Núm. 14

octubre 2018-marzo 2019
La irrisión de la masculinidad hegemónica

en la puesta en escena de Prata Paraíso

Daniel dos Santos Colin

\section{Ficha técnica de Prata Paraíso}

Dirección: João de Ricardo.

Texto: El grupo (libremente inspirado en Pterodactyls, de Nicky Silver).

Elenco: Andrew Tassinari, Douglas Jung y Eduardo d'Ávila.

Banda de sonido pesquisada, vestuario y maquillaje: El grupo.

Iluminación, videos y espacio: João de Ricardo.

Duración: 105 min.

Estreno: enero de 2017, en la Usina do Gasômetro (Porto Alegre, Brasil).

El espectáculo recibió los Prêmios Açorianos de Teatro 2017 (sMC-Porto Alegre) de Mejor Espectáculo y Actor (Andrew Tassinari). 